\title{
Commentary: A journey of a thousand miles ...
}

\author{
Frederick A. Tibayan, MD
}

A famous observation, attributed to Lao Tzu, that any great undertaking "begins beneath one's feet," 1 could be applied to the process of becoming a cardiothoracic surgeon. Suarez-Pierre and Yang $^{2}$ provide a guide to the dizzying array of opportunities available to medical students and surgical residents in the early stages of their interest in the field.

This Young Surgeons Note is exceptional for multiple reasons. First, it represents what must be the most comprehensive table of scholarships, fellowships, awards, and funding opportunities ever compiled for our specialty, and hyperlinked to boot! Having attempted to put together such a list both as a lab resident and mentor, I can appreciate the effort required and the benefits to come. Second, because the article is presented in print and online, this critical information is available to any prospective trainee or mentor in the country or world. This will enable a broader pool of applicants to these opportunities, raising the quality and diversity of the participants and, ultimately, our future colleagues.

The scope of the article is necessarily limited by the format to key pointers on how to make use of the guide. A central role of mentors (and possibly future articles) will be to help mentees take the next steps, including choosing the right opportunity, putting together a successful application, making the most out the interview experience, and following-up afterward.

Those who have taken advantage of traveling fellowships, competitions, and awards will attest to the

\footnotetext{
From the Division of Cardiothoracic Surgery, Department of Surgery, Oregon Health \& Science University, Portland, Ore.

Disclosure: Author has nothing to disclose with regard to commercial support.

Received for publication Feb 26, 2020; revisions received Feb 26, 2020; accepted for publication Feb 27, 2020; available ahead of print March 19, 2020.

Address for reprints: Frederick A. Tibayan, MD, Division of Cardiothoracic Surgery, Department of Surgery, Oregon Health \& Science University, 3181 SW Sam Jackson Park Rd, Mail code: L353, Portland, OR 97239 (E-mail: tibayan@ohsu.edu). J Thorac Cardiovasc Surg 2021;161:1395 0022-5223/\$0.00

Published by Elsevier Inc. on behalf of The American Association for Thoracic Surgery

https://doi.org/10.1016/j.jtcvs.2020.02.126
}

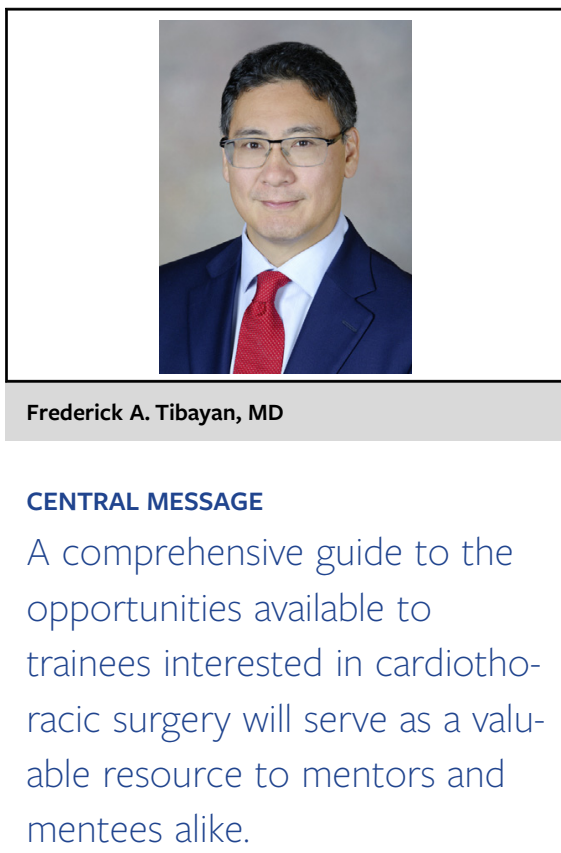

importance of such experiences not only in the successful application to cardiothoracic surgery training programs, but also in the cherished lessons and relationships they carry with them throughout their careers. This article serves as a roadmap for part of the long and winding road toward becoming a cardiothoracic surgeon. We should all share this Young Surgeon's Note with a promising individual or forum for trainees to help them along this journey of a thousand miles.

\section{References}

1. Mitchell S. Tao Te Ching: A New English Version. New York: HarperCollins; 1988

2. Suarez-Pierre A, Yang SC. Scholarships in cardiothoracic surgery-a guide for surgical trainees. J Thorac Cardiovasc Surg. 2021;161:1390-3. 